\title{
Different Hype Cycle Viewpoints for an E-Learning System
}

\author{
Logica Banica $^{1}$ \\ ${ }^{I}$ Faculty of Economics, University of Pitesti, Romania
}

\begin{abstract}
This paper uses Gartner Group's Hype Cycle as an analysis tool for the e-learning platform integration process at the University of Pitesti. The platform was installed three years ago and during this time there were many points of view (by major user groups) regarding the usefulness and adoption rate. Based on this fact, according to us, the e-learning Hype Cycle has two graphical representations, two variation curves that have the first part identical but differ significantly in the following two stages, differences that disappear in the end. Based on our analysis, we found necessary to improve the management strategies, to better motivate the teachers in order for them to reach the same level of interested shown by the students in using the system, and thus bringing the two educational groups to the same opinion. We have depicted all this evolution and the different points of view by the Hype Cycle curve, that should be only one for the 5th year of system presence in our institution, a convergence reached a bit too late in the IT world, where software solutions have a limited life cycle.
\end{abstract}

Keywords: Hype Cycle, e-learning, academic collaboration

\section{Introduction}

This paper is a new approach of our research on learning systems related to the academic domain: elearning. As e-learning researcher and teacher, we have done the comparison between e-learning systems and traditional learning systems and the results were presented in previous scientific papers. Thus, we made the assumption, later confirmed by practice, that e-learning is a new method that opens a convenient way to enhance educational management and offers the universities unparalleled documentation, research and collaboration opportunities in an integrated environment [1].

Currently, many universities have deployed open-source and commercial licenses for e-learning platforms, like Blackboard, Moodle, Dokeos, ILIAS and Adobe e-learning.

A traditional learning management system (LMS) has, even now, some advantages, such as good communication between teacher and student and an important level of student involvement, but e-learning, despite its drawbacks related to the reduced interaction between the two and the possibility that the student's long-term focus may be affected by the environment, has even more important advantages, like the development of teamwork skills or the opportunity to follow the course at his own pace [2].

In addition, an e-learning system delivered by means of Cloud Computing offers an open window to the academic world for the universities, especially those without the resources to improve their educational offer and services in the near future [3].

Starting from the new analysis technique based on graphical representations for technologies and information systems, launched by Gartner and called Hype Cycle, we have concentrated our efforts around an elearning system implemented in 2011, and we are evaluating its impact today, after 4 years of continuous usage. By dissecting this phenomenon and from our experience, we have found out that the point of view of the students and the one of the teachers using this system have many discrepancies.

The paper aims at discussing these aspects and look for explanations that will be offered to the other researchers interested in this domain.

Our work is divided in two sections and a Conclusions part. Section 2 presents the two concepts involved (Hype Cycle and e-learning), summarizing some of the background material, and investigates how the hype curve can be used to determine the status of an e-learning system. Section 3 includes the analysis of the current state of the e-Learning platform in the University of Pitesti, Romania, based on Hype curve, discussions and results for some potential research strategies.

Conclusions close the paper, and suggest ways of improvement of the adoption ratio for the e-learning platform in recent future. Here we include a series of answers inspired from our own research activity and implementation experience, and we propose an important question for the community.

\subsection{Gartner Hype Cycle}

\section{Literature Review}

Gartner, along with Aberdeen, IDC and Forrester are research companies specialised in providing information about technologies and software products to client firms, in order to influence their future choices. 
It can be said that Gartner's research dominates the practical side of technology, with their published studies high in the attention of both the business and academic worlds.

Even though the Hype Cycle tool was introduced by Gartner in 1995, this analysis method only became popular after 2005, when extensive testing has proved its usefulness and reliability.

According to Gartner Group [4], the Hype Cycle is ,,a graphical representation of the life cycle stages a technology goes through from conception to maturity and widespread adoption".

Hype curve is designed to describe a typical progression of an emerging technology to its eventual position in a market or a domain [5] and to guide technology decisions of the companies.

In essence, „hype" refers to the cyclical waves of enthusiasm and disenchantment that every new technology is issuing within the community of interested people.

As depicted in Fig. 2, there are five stages of the Hype Cycle: Technology Trigger, Peak of Inflated Expectations, Trough of Disillusionment, Slope of Enlightenment and Plateau of Productivity. These five different steps may theoretically occur, but not all of them are necessarily occurring for each technology.

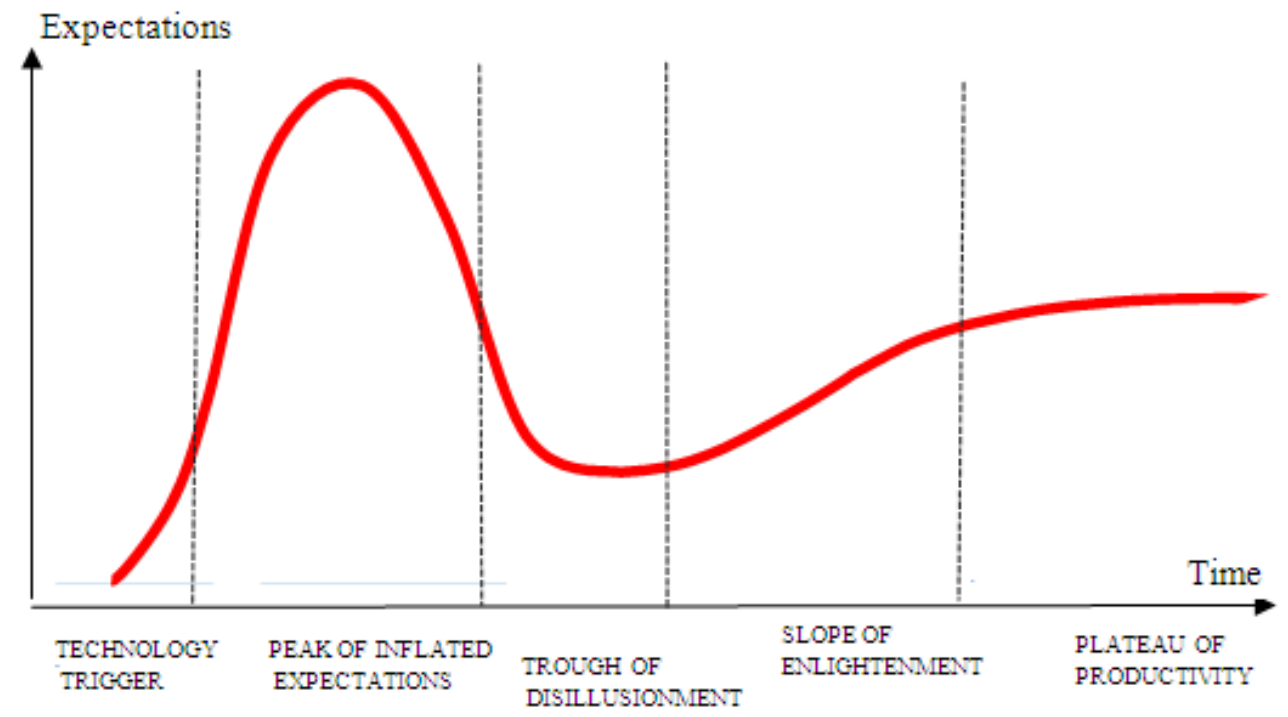

Source: Gartner Inc. (www.gartner.com)

Fig. 2. Hype Cycle phases

In some cases a stage may not occur or a new phase can be added.

In the following, we will present a brief description of each phase [4]:

a. Technology Trigger - A new technology is conceptualized and media disclosures trigger significant publicity. It is known that some of the technology's advantages and drawbacks are not obvious at this moment, since it was not yet evaluated in real life scenarios.

b.Peak of Inflated Expectations - The technology is implemented by a few brave firms and a powerful animation around the subject arises, that may influence (or not) the companies. But, the expectations are high and the information about the technology is not enough, and also is not known how it will be applied in firms.

During this stage, researchers from the academic environment and students are invited to anticipate how the technology will influence companies and about the potential benefits.

c. Trough of Disillusionment - Flaws and failures of the implementations and also the overinflated expectations of the previous stage lead to some disappointment regarding the technology. The research and the investments in the technology will continue only if the providers improve the product or the implementation conditions are changed and the problems are solved.

d. Slope of Enlightenment - The technology's benefits become clearer and the number of firms that want to adopt it for their business increases, assuming the risk of failure. At this stage, the research is focused on the results of case studies, in order to follow the trend and to find the best practices for use. A grouping of case studies from the slope of enlightenment can provide insights for the next level, the plateau of productivity [6][7]. e. Plateau of Productivity - The technology demonstrated its viability and becomes widely implemented, it is well known on the IT market and its level of risk is reduced as a growing number of firms have implemented the technology. At this stage, the firms may have a measure of the technology's benefits.

From this point forward, research studies are conducted for measuring the usability and the potential value created by implementing the technology. Thus, conclusions arise and improvements can be added in order to polish the aspects that are still not perfect (2nd generation). 


\subsubsection{Drawbacks of Hype Cycle}

This new tool seems to be a template applied to the IT technologies and is hard to accept the fact that all these, whatever their nature is, fit into the same pattern. Among the many criticisms, one related to the name of the graphical tool is often invoked: it is not a cycle and does not reflect changes over time in the rate at which they occur.

Another weakness is that Hype Cycle has no profits from the development or marketing of the new technologies, but it may influence trends. Also, the boundaries between any two phases have a degree of subjectivity and are different from one person to another in terms of expectations, disillusionment and enlightenment, that cannot be understood in the same way by each user.

The points on the graphical curve may induce wrong ideas regarding the use of the technology. It is interesting to interpret the user attitude in the Trough of Disillusionment phase: whether he should stay away from the technology or to accept the perspective to continue and to evolve with technology to a next phase.

\subsubsection{Some examples of latest Gartner Hype Cycles}

In the last time, Gartner publishes an annual report, Gartner's Emerging Technologies Hype Cycle that helps businesses understand which emerging and embryonic trends they should examine for competitive advantage [8]. In the 2011 issue, they showed that fast movers from 2011 include Big Data, 3D printing, cloud computing, media tablets, and near field communications (NFC).

The 2012 edition reveals the fact that the evolution of these technologies was tempered by those technologies in each potential scenario that have yet to reach their tipping point.

Cloud-related Gartner report for 2012 reveals that business opportunities offered by the cloud platforms are becoming clearer, and thus interest for this domain is at the highest point, and the technology is ready for mainstream adoption in the next three years.It could be said that this way of processing data is approaching the Trough of Disillusionment [10].

Also, there are predictions that many of today's technologies will change significantly in the next few years, and the future of cloud computing, large-scale advertising or virtualization is hard to foresee just by looking at the products currently present on the market.

In 2013 Digital Marketing Hype Cycle latest techniques, such as content marketing, attribution, responsive design and mobile analytics evolved quickly from the innovation trigger stage to the peak of the hype cycle [11].

In 2013, Gartner followed with their Hype Cycle of emerging technologies [9] and the companies who are interested in new technologies saw that Big Data is near the Peak of Inflated Expectations. Other new technologies to watch in the future are the Brain-computer interface, Human Augmentation and Neuro-business. Very interesting was also the 2013 Gartner Hype Cycle for Education (Fig. 2), focused on digitalization trends related to learning technologies [12].

Technologies such as Quantum and Affective Computing are on the rising trend, whilst Big Data, Social Software standards and MOOC (Massive Open Online Course) are at the peak. Some ideas like BYOD strategies (Bring your own device) and Social Learning Platform for Education are sliding into the Trough of Disillusionment stage. An increases evolution had Tablets, Open-Source Learning Repositories that are climbing the Slope of Enlightenment phase.

Mashups, defined as web applications that use content from more sources to create a single new service displayed in a single graphical interface, are reaching the Plateau of productivity. E-Book readers and SelfPublishing applications are also entering the Plateau of productivity phase.

By using the Hype curve, many institutions, amongst which some universities can be found also, have achieved an evolution of their educational instruments and techniques, as a customization of the Gartner Hype Cycle. As an example, we can quote the University of Minnesota and the one in Oulu, Finland [5]. 


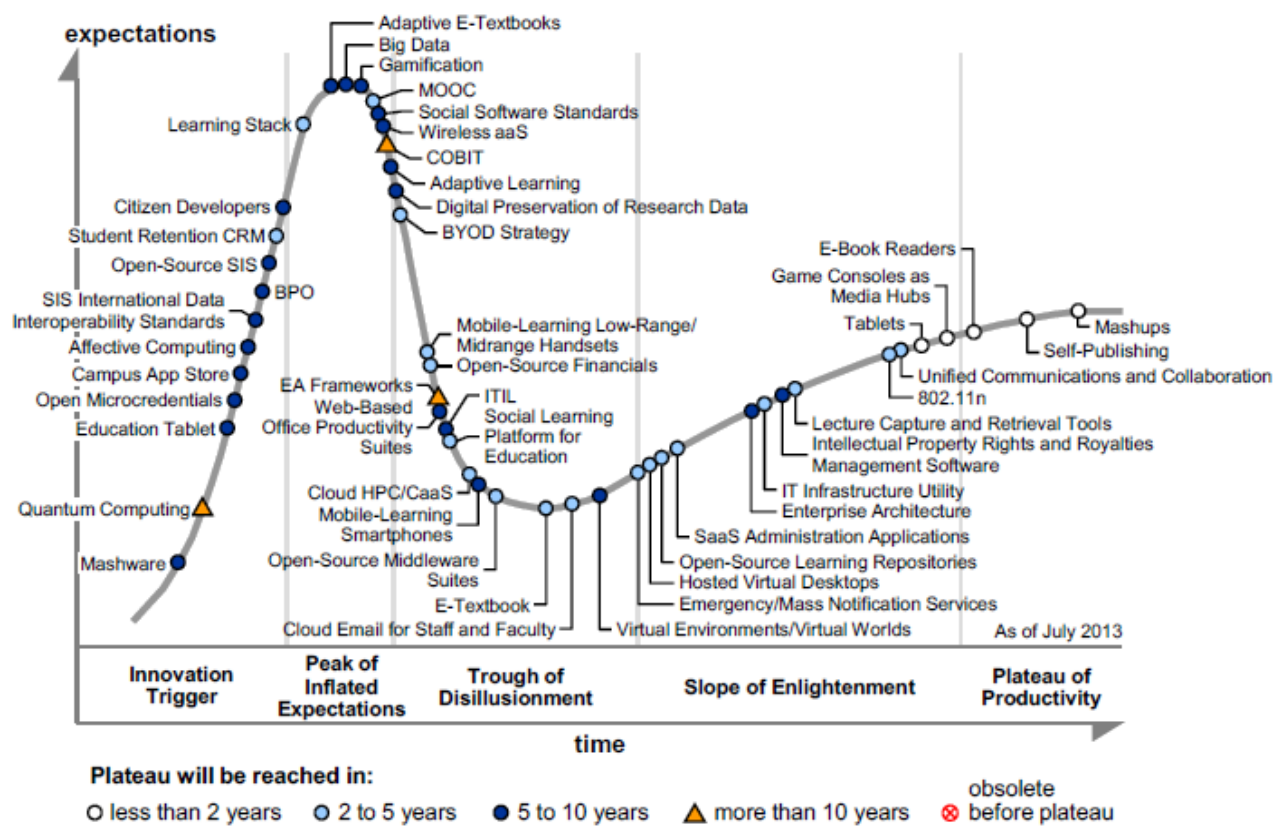

Source: Gartner Inc. (www.gartner.com)

Fig. 2. Hype Cycle for Education, 2013

\subsection{Briefly about e-learning}

Universities all over the world are using their own learning management systems, generally based on open source e-learning platforms and are having integrated collaborative software platforms.

It is important that academic content delivery systems are paired with a collection of collaboration tools that are able to maximize the interaction between the parties involved in the learning process. Applications like wiki pages, chat rooms and blogs are offering better support and facilitate the acquirement of knowledge, if they are used to their full potential in the academia, as they are in high-schools and other learning environments.

By using such tools, teachers are able to provide more personal advices for the students, continuously monitor their progress and students are able to communicate more efficiently between them in order to evolve faster. Resource sharing and exchanges of ideas are the perfect helpers for an interested person that wants to know more about the topics proposed for study by the teacher.

Some frequently used open-source web-based applications that include such technologies, are Moodle, Claroline, MIT.LRN, Dokeos and ILIAS. Commercial solutions often provide more features, are scalable on larger scale and include powerful security policies - as they are integrated systems.

In our case we will focus on IBM ${ }^{\circledR}$ Workplace Collaborative Learning ${ }^{\mathrm{TM}}$ (WCL), implemented at our university with the help of UE funds, a portal-based learning solution that allows fully localized course and classroom management, online and off-line course planning, it is SCORM compliant and integrates the power of Sametime collaboration suite (live chat, blogs and wikis) along with audio and video conferencing. [13].

It's a form of distance learning through the Internet, which facilitates dissemination of the information on a technological platform (Learning Management System) in which learners have access to educational content published by the teachers and they can approach individual and group learning activities.

Online teaching, that may be synchronous and asynchronous, and allows checking student's activities, so the teachers and the tutors benefit by this way of evaluation [2].

Being an e-learning 2.0 system, WCL provides many advantages:

- encourages contact and cooperation between professor and students;

- allows cooperation among students;

- develops active learning;

- emphasizes time on task activities;

- respects individual ideas and individual ways of learning.

Having integrated collaborative software services, WCL removed many inconveniences, first of all because the connected users are authenticated by a security system (directory-based SSO), then considering the established relationships by respecting the educational institution ethics and finally, given that there is an academic context which involves knowledge sharing, directed learning, leaving room for creativity. 
Success or failure of integrating the e-learning platform in the academic environment depends largely on the chosen pedagogical approach and the online offer of educational materials. A discussion of the educational potential of collaborative software, and other tools, needs to be started from the point of view of an understanding and description of specific learning activities [14].

This way of teaching brings the involved groups closer and offers the context for real-time discussions using shared whiteboards and chat, for easy publication in weblogs and wikis, thus giving birth to a complete new world, the Virtual Classroom - Fig. 3.

Management of the learning and evaluation activities is simplified, and teachers have flexible options in guiding the students to achieve their goals. The scheme shows that teachers give to their students some learning items, called Learning Objects, and may cooperate with their learners maintaining a professional relationship, by building weblogs and wikis for courses or projects. That is also the appropriate way to allow the communications among the students related to a course or project.

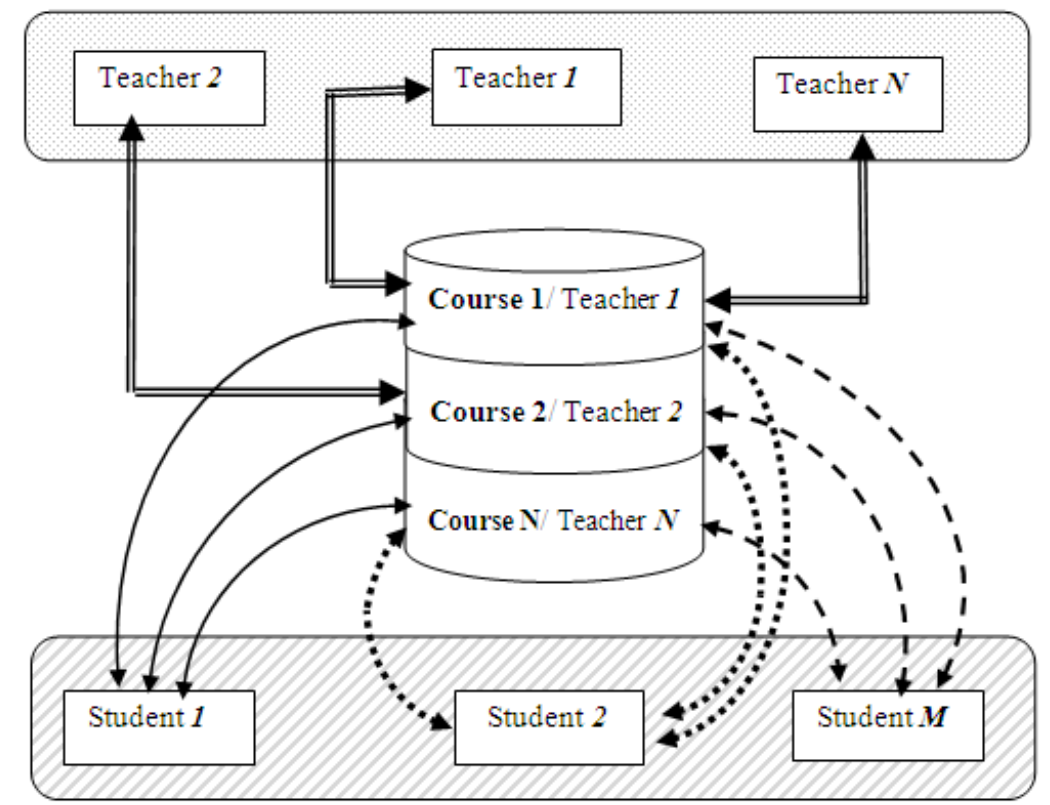

Figure 3. The interactivity teacher-student using WCL collaborative tools

\subsection{Hype cycle for e-learning}

\section{Methodology}

In this paper, Gartner Hype Cycle is used as a basis to analyse the process of integrating the e-learning platform in the educational activity of the University of Pitesti, in the 4th year after deployment.

Since the beginning in January 2011, the IBM WCL 2.7 platform has been on a rising path of adoption, reaching the Peak of Inflated Expectations in less than a year. In this timeframe, teachers and students have had similar opinions regarding the usefulness of the system for their activity and its visibility in the academic world. Then, after the first year of use, the feelings about the platform headed to the Through of Disillusionment stage, which lasted for about two years, and whose causes we will investigate in this section. It is worth mentioning that in this phase, the differences between student and teacher points of view grew significantly.

Thus, in our vision, the e-learning Hype Cycle has two graphical representations, with two variation curves that have the first part identical, and then they evolve differently for the next two stages, in order to reunite in the last phase - the Plateau of productivity, as presented in Fig. 4.

The first Hype curve represents the point of view of teachers (Teacher Model) and the second proposed solution corresponds to the student opinions (Student Model). Both of them involve a different perception, provided by their needs and efforts.

\subsection{Student point of view}

The implementation of the IBM WCL e-learning platform was widely discussed and presented throughout the University and other educational institutions in the country at the moment of inauguration, and thus the moment of public availability was expected with a high degree of interest by both the students and the teachers alike.

In the first year, the interest kept rising and reached the peak, when teachers from all faculties have loaded their curses on the platform and encouraged their students to enter the virtual learning environment. 
Their participation, usage ratio and the appreciation for modern Web 2.0 technologies have proven that the students have been enthusiastic in benefiting from this form of study and collaboration. The fact that they are using e-content, they can express their opinions regarding the course and develop their own items, they can talk directly to the teacher and other classmates are the strong points that have attracted learners to the WCL platform. A powerful influence had the Department of Part-time Education of the university on information dissemination through several programs, evaluated at national level, in 2012.

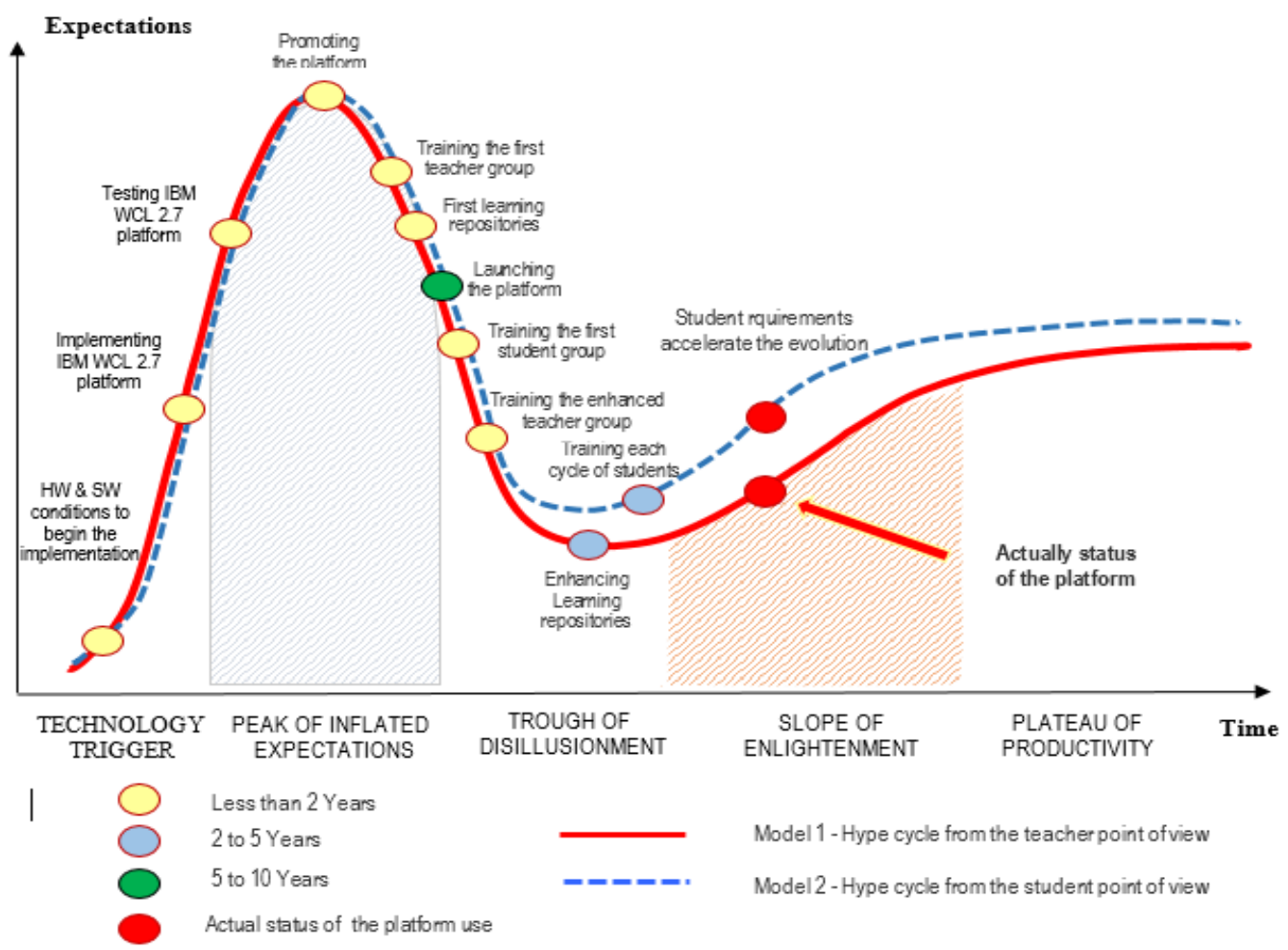

Fig. 4. Hype Cycle models of e-learning platform

The students of this department rely on remote learning more than the students that have to be present in campus day by day. Their use ratio of the platform was above $50 \%$ from the first year of availability.

By following the natural evolution of the Hype Cycle, the downward direction is explained, on the one side by too high expectations, which were not addressed as forecasted (e.g. web conferencing, collaborative software), and on the other hand because a relatively small percent (10\% to $30 \%)$ of the teachers have mastered the procedures to manage the platform in order to upload their study material and then enrol the students in discussions. Also, some technical issues in the data centre (frequent power losses, lack of an independent power generator, heating) have had their contribution to the Disappointment stage.

Figure 4 shows clearly that students found the resources to pass over this stage much quickly and to reach the Slope of Enlightenment, phase in which we find ourselves today.

Though, the progress has to be backed up by the attitude of the teachers and by technical measures to keep the platform operational and highly available, and thus allow reaching the Productivity phase in the 5th year.

\subsection{Teacher's angle}

Though preferred as a working strategy, e-learning technology involves supplementary didactical activities for the professors. Firstly, they need to learn how to use new software, and then convert their teaching material in the SCORM format and upload that to the platform. The collaboration activities also involve precious time from the teacher schedule. That leads to a longer and more important phase of Through of Disillusionment for the teachers, after the first two stages that were surpassed rapidly.

It is also worth mentioning that the longer stay of the teachers in the disappointment zone and the slower evolution to the uprising part of the curve is negatively influencing the process of reaching the Plateau of productivity in the e-learning process by the students also. The cause is clear: the platform is not offering enough learning resources and thus is not used at its full capacity. There are some hesitations in using the online evaluation tools and the student progress reports that the portal offers in order to simplify the grading process. 
Another negative aspect of the situation is the fact that, after a year of inactivity, training is required for the teachers in order for them to use the authoring tools and convert their courses.

The learning cycles of 3 years for undergraduates and 2 years for the master students involve the training of newcomers each year, to help them fully benefit from the available resources.

\section{Discussions And Proposed Solutions}

Certainly, this is a subjective interpretation based on our own observations concerning the effects of elearning platform implementation in our University. There are many ways to make this process more efficient, starting from management policies that would motivate the teachers and train them properly, and continuing with hardware improvements that would support online video conferences, group working and other methods that will attract students to this way of learning.

In order to achieve a better adoption, we suggest that each year there could be organised three meetings (of 4 hours) in each faculty, in order to help fresh students and the others to become familiar with the opportunities provided by the platform.

From our analysis it can be deducted that student interested and platform usage ratio are directly connected with the effort from the teachers to offer updated study materials, to communicate with the students and to support their efforts through collaborative software, and also with the availability (uptime) of the platform. An important role in this context is given to the upper management of the institution, which should make steps in the direction of motivating the teachers to involve in this initiative, in order for them to reach the same level of interest as the one shown by the students - in the graphical representation, to reach an overlapping of the requirements and educational offer from the two groups.

We have presented the evolution, both positive and negative, of the process, and the different points of view of the involved parties, by the two models of the Hype curve, and we are convinced that we should have an overlap of the two representations in the 5th year of use, a somehow late achievement, given that in the IT world any product has a limited, relatively short life cycle.

\section{Conclusions}

Current trends in education are increasingly focusing on e-learning, characterized in the academic environment by elaborated documentation, which undergoes many transformations: drafted, revised, rewritten, edited, proofread, finalized in comparison with information and comments of learners, that may be unedited, spontaneous, most of it being an expression of thoughts, ideas published on blogs or wikis. But, this is not a war; we think this is the expression of a strong collaboration, one of the parts providing knowledge and experience, the other part providing originality with a fresh thinking and enthusiasm.

Using other type of education tools, the academic world is changing and the universities can be part of the new wave and involve in the development of these emerging genres, or they may chose the traditional learning system and could be marginalizing themselves.

This paper follows studies conducted by Gartner Company on education environment using Hype Cycle as graphical tool. But, the article is an empirically driven study of the evolution for the educational use of the e-learning platform implemented at the University of Pitesti, by means of the Hype curve.

From the studies performed on different Hype Cycle viewpoints of the e-learning platform, it is revealed that there are two models, each of them having its advantages and drawbacks, but we believe these cannot be the perfect solution for all kinds of use-cases. Hype Cycle applied to the educational process motivates the advantage of using emergent technologies together and emphasizes the attraction of the new generations of students to the activities of self-paced learning and shared knowledge opportunities, and their low interest for traditional ways of teaching.

In the final section of this paper, and based on the foregoing, as researchers we will continue those learning experiences in the next year, and we will follow the evolution of the e-learning platform with Hype Cycle, and, as teachers, we will try to increase the usage percent of this system, especially the interactivity teacher-learner, without affecting the quality of student education.

\section{References}

[1] Banica L., Stefan C., Rosca D, Enescu F., Moving from learning management systems to the e-learning cloud. AWERProcedia Information Technology \& Computer Science. [Online]. 2013, 04, pp 865-874. Available from: www.awer-center.org/pitcs

[2] L. Banica, V. Paun, L. C. Stefan, Integrating Web 2.0 in the e-learning process, Proceedings of 3nd International Conference EBEEC 2011, Pitesti, Romania

[3] Banica, L., Stefan, C., Jurian, M, Business Intelligence for Educational Purpose, Proceedings of the International Conference on Engineering \& Business Education, Innovation and Entrepreneurship, Sibiu, BRCEE 2012

[4] http://www.gartner.com

[5] Jari Laru and Sanna Järvelä, Using Gartner's Hype Cycle as a basis to analyze research on theeducational use of ubiquitous computing,2013, 
http://www.academia.edu/3773533/Using_Gartners_Hype_Curve_as_a_basis_to_analyze_research_on_the_educational_use_of_ubi quitous_computing_CSCL_2013

[6] Daniel E. O'Leary, Gartner's Hype Cycle and Information System Research Issues, IRSAIS - International Research Symposium on Accounting Information Systems, December 2007, Montreal and at the American Accounting Association National Meeting, 2008

[7] Fenn, J., “Understanding Gartner's Hype Cycles,” 2007, 5 July 2007.

[8] Hung LeHong and Jackie Fenn, Key Trends to Watch in Gartner 2012 Emerging Technologies Hype Cycle, Gartner, Inc. , http://www.forbes.com/sites/gartnergroup/2012/09/18/key-trends-to-watch-in-gartner-2012-emerging-technologies-hype-cycle-2/

[9] Hype cycle Research Methodology, http://www.gartner.com/technology/research/methodologies/hype-cycle.jsp

[10] Dave Chaffey, Latest Gartner Hype Cycles, 2013, http://www.smartinsights.com/managing-digital-marketing/marketinginnovation/technology-for-innovation-in-marketing/

[11] Rick Blaisdell , Hype Cycle for Cloud Computing from Gartner: SaaS Most Promising Technology, 2013, http:/www.rickscloud.com/hype-cycle-for-cloud-computing-from-gartner-saas-most-promising-technology/

[12] Jan-Martin Lowendahl, Gartner Hype Cycle for Education, 2014

[13] $\begin{array}{lllllll}\text { IBM } & \text { Workplace } & \text { Collaborative } & \text { Learning } & 2.7 & \text { Product }\end{array}$ http://publib.boulder.ibm.com/infocenter/wclhelp/v2r7m0/index.jsp?topic=/com.ibm.help.learning.doc/wcl_po_productoverview_c. html

[14] Anderson, T. , Teaching a Distance education course using educational social software, 2006 http://terrya.edublogs.org/2006/01/02/teaching-a-distance-education-course-using-educational-social-software/ 